p-ISSN 1693-1246

e-ISSN 2355-3812

June 2020
Jurnal Pendidikan Fisika Indonesia 16 (1) (2020) 57-62

DOI: 10.15294/jpfi.v16i1.17491 http:/journal.unnes.ac.id/njulindex.php/jpfi

\title{
Impact of Magnetic Field Strengthening on Combustion Performance of Low-Octane Fuel in Two-Stroke Engine
}

\author{
N. A. Wibowo ${ }^{1,3 *}$, S. M. Utami ${ }^{1}$, C. A. Riyanto ${ }^{2,3}$, A. Setiawan ${ }^{1,3}$ \\ 1'Department of Physics, Universitas Kristen Satya Wacana, Indonesia \\ ${ }^{2}$ Department of Chemistry, Universitas Kristen Satya Wacana, Indonesia \\ ${ }^{3}$ Study Center for Multidisciplinary Applied Research and Technology, \\ Universitas Kristen Satya Wacana, Indonesia
}

Received: 30 January 2020. Accepted: 26 March 2020. Published: 30 June 2020

\begin{abstract}
The impacts of strengthening magnetic field exposure on combustion performance of low-octane fuel have been examined experimentally. The combustion test was carried out using a 2-stroke 49 cc engine where the fuel was magnetized using a low magnetic field $(<2 \mathrm{kG})$. Moreover, the molecular behavior of magnetized fuel was also characterized through spectrum tests using NIR and UV-Vis spectrophotometers. The result of this study indicates an exponential decrease of magnetized fuel consumption against the strengthening of magnetic field exposure. This exponential decrease of consumption can be related to the Arrhenius principle. In addition, the decrease of oxygen in the exhaust gas along with the strengthening of the magnetic field also confirms the increase of combustion reactions. Meanwhile, the increase of magnetized fuel absorption against ultraviolet and near-infrared lights along with the increase of the magnetic field intensity indicates a bond weakening, accompanied by the increase of molecular vibrational energy.
\end{abstract}

Keywords: Combustion; Fuel; Magnetic; NIR; UV-Vis

\section{INTRODUCTION}

Although diversification of the driving energy sources of motor vehicles has been proposed, such as the use of electric batteries, fossil fuel has still been the main energy used. Considering the limited supply of non-renewable fossil fuel sources, various efforts have been made to make the use of this fuel type more efficient. In his writing published in SAE International, Abdel-Rehim \& Attia (2014) stated that efficiency of fuel consumption and level of pollutants in exhaust gas were determined by the completion level of combustion process in an engine. Therefore, an effort to improve combustion performance is an urgent issue because it is not only related to the limited mineral resources, but also to the environmental pollution.

Various methods have been carried out to optimize combustion performance. One of the promising methods in reducing exhaust gas emission as well as fuel consumption is the use

${ }^{*}$ Correspondence Address:

Jl. Diponegoro 52-60 Salatiga 50711

E-mail: nurajiwibowo@gmail.com of magnetized fuel (Okoronkwo et al, 2010). The use of magnetized fuel has been believed to increase engine combustion performance, observed from the reduced fuel consumption. This is based on several previous studies (Faris et al., 2012; Mane \& Sawant, 2015; Vivek, Nikhil, \& Lutade, 2013), which stated that by using fuel exposed to strong magnetic fields (>2 kG), combustion performance on the engine would increase. However, technically, the use of large magnetic fields is not relevant enough to be applied to motor vehicles. In addition to having an impact on the performance of other electronic instruments, it also requires enormous power to generate such a strong field.

The significance of the impacts of magnetic field exposure on combustion performance is influenced by several aspects, namely type and volume of machine (Jain \& Deshmukh, 2012), workload or engine rotation (Faris et al., 2012), duration of exposure (Abdel-Rehim \& Attia, 2014), and type of fuel (Abdel-Rehim \& Attia, 2014; Tao \& Xu, 2006). Although some experiments have proven the impacts of exposure, the fundamental reason that causes the use of fuel exposed to the field 
to increase the completion level of combustion has not been yet known with certainty. Therefore, research to obtain information related to the physical characteristics of fuel after being exposed to magnetic fields, both its energy and molecular motion, has become particularly important to be conducted to provide fundamental knowledge more comprehensively.

The molecular physical characteristics of a liquid, whose main constituent molecules are hydrocarbons $(\mathrm{HC})$, such as fuel, can be identified using spectrum measuring devices such as UV-Vis (Ultraviolet-Visible) (Silva et al., 2015) and NIR (Near-Infrared) spectrophotometers. These two spectrophotometers have advantages in terms of ease of sample preparation and speed of analysis (Lachenal \& Ozaki, 1999; Pasquini, 2003; Silva et al., 2015).

The first objective of this study is to determine the impacts of strengthening of the magnetic field exposure $(<2 \mathrm{kG})$ on the completion level of combustion of low-octane fuel. Considering that the exhaust gas content also indicates the completion level of combustion (Chalid et al., 2005), the measurement of the completion level of combustion is not only viewed from the amount of fuel consumption, but also from the oxygen $\left(\mathrm{O}_{2}\right)$ content in the exhaust gas. In this study, $\mathrm{O}_{2}$ is a gas element which was measured directly because of its important contribution in the combustion process (Schell, Schram, \& Ross, 1988). The second objective of this study is to examine the impacts of strengthening of the magnetic field exposure on the molecular characteristics of fuel through observation of the fuel absorbance or transmittance level in the spectrum of UV-Vis and NIR rays.

\section{METHOD}

In this study, a 2-stroke engine with a cylinder capacity of $49 \mathrm{cc}$ was used as a testing engine. This type of machine was chosen due to its simpler working system (only 2 steps) that allows a faster combustion process with more fuel consumption. The fuel used a premium type of low-octane fuel mixed with 2-stroke engine oil with a ratio of 20:1. The changes in fuel consumption levels are expected to be more observable at short burning time intervals (in minute order) by combining the use of simple engine and low-octane fuel.

To observe the impacts of strengthening of the magnetic field exposure, the fuel was magnetized with various intensities of magne- tic fields. Neodymium N35 permanent magnet was used as the source of magnetic field. This type of magnet was chosen because its field intensity is quite large. In the distance range of $1.5-16 \mathrm{~cm}$, the field intensity is in the range of 6-1600 Gauss. To measure the intensity of this magnetic field, a DX-103 Gaussmeter magnetic sensor was used with a sensitivity level of 0.1 Gauss. The experimental scheme is shown in Figure 1.

Characterization of molecular physical properties of magnetized fuel was carried out through spectrum investigations. To observe the existence of molecular vibrational motion, an NIR spectrophotometer was used. To investigate the molecular binding energy, a UV-Vis spectrophotometer was used.

At the combustion performance test stage, the magnetized fuel in a closed oil tank was flowed through a plastic hose to a test engine whose workload had been set. The engine workload was measured by its rotation speed. In this study, four different levels of workload were used. The combustion performance examination was carried out by observing the fuel consumption level and $\mathrm{O}_{2}$ content in the exhaust gas. The $\mathrm{O}_{2}$ content in the exhaust gas was measured in real-time using a sensor connected to the data acquisition and a computer through the interface and control devices.

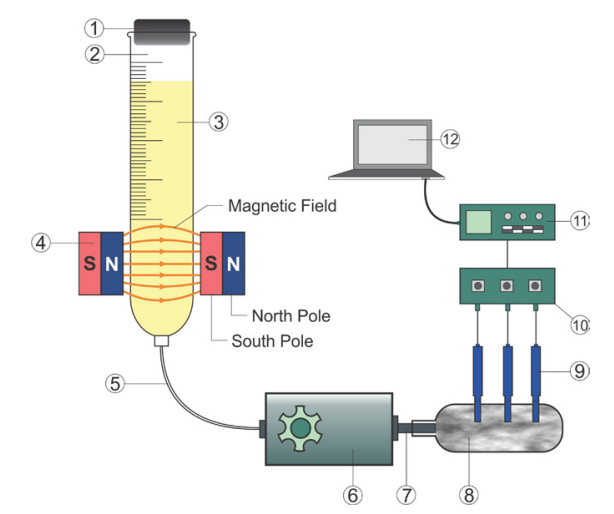

Image captions:

\begin{tabular}{|l|ll|}
\hline 1. Rubber cover & 8. & Exhaust gas tube \\
2. Oil tank (1 mm scale) & 9. & Multi-sensor \\
3. Fuel & 10. & Data acquisition \\
4. Neodymium N35 magnet & 11. & Interface and control \\
5. Plastic hose & 12. & Computer equipped with data \\
6. 2-stroke 49 CC engine & & control and processing software \\
7. Gas drain & & \\
\hline
\end{tabular}

Figure 1. Experimental scheme

\section{RESULT AND DISCUSSION}

Fuel is mainly composed of the $\mathrm{HC}$ chain. Naturally, HC molecules experience inter-molecular interactions in the form of attraction. This 
interaction has an impact on the cluster formation of relatively strong $\mathrm{HC}$ molecules, which is often called clustering (Hamdhani et al., 2016). An understanding of the molecular energy involved and its modification is important in an effort to optimize the combustion reaction.

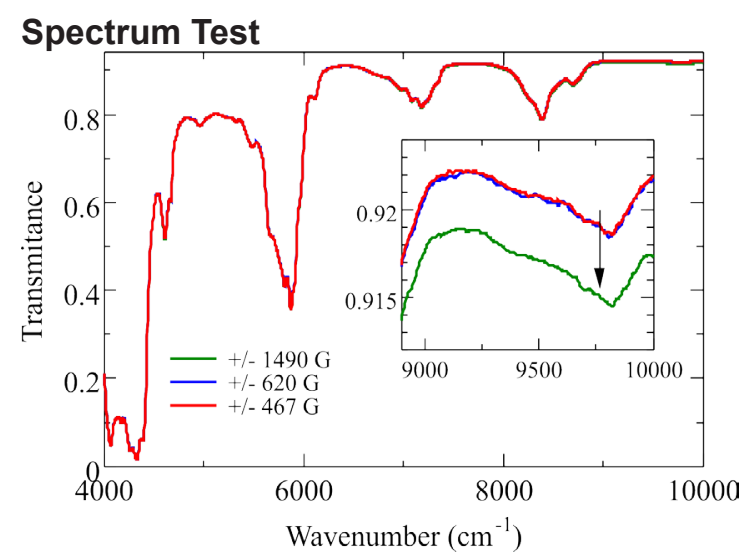

Figure 2. Spectrum curves of fuel transmittance scanned with NIR spectroscopy

Figure 2 shows the spectrum curves of fuel transmittance, scanned with NIR spectrophotometer, of the fuel exposed to magnetic fields. At three different levels of magnetic field intensity, the spectrum curves of fuel show similar shapes. This indicates that the magnetic field exposure to the given range does not modify the chemical structure of the fuel. However, there is a difference in the level of transmittance at high energy $\left(8800-10000 \mathrm{~cm}^{-1}\right)$. Transmittance in the range of this wave numbers is related to molecular vibrations of $\mathrm{HC}$ (Yu et al., 2018). When the magnetic field exposure is stronger, the transmittance intensity decreases. This decrease is caused by the increasing number of electromagnetic waves absorbed by the $\mathrm{HC}$ molecules. The relation between transmittance $(T)$ and absorbance $(A)$ is expressed in the following Beer-Lambert equation:

$A=-\log T$

The absorbed electromagnetic energy is used to increase the molecular vibrational energy. This increase of vibrational energy indicates the occurrence of polarization and adjustments in dipole moments due to displacement and alterations of the magnetic moment orientation of the $\mathrm{HC}$ molecules.

The vibrational frequency of $\mathrm{HC}$ molecules determines the amount of molecular binding energy. The higher the frequency is, the weaker the bond gets. This causes fuel viscos- ity, which is influenced by binding energy (Faris et al., 2012), to decrease after being exposed to magnetic fields. The high absorbance, which indicates higher vibrational frequency, refers to lower molecular bonds, so that the energy needed to break the inter-atomic bonds is also lower. The increase of fuel absorbance intensity along with the strengthening of magnetic field exposure indicates the weakening of molecular binding power (Nufus et al., 2017b).

Every time electromagnetic wave hits a compound, the energy carried by this wave has an opportunity to excite electrons in the compound to the energy level above. If the amount of energy carried by this wave is equivalent to the energy gap, then the electrons will absorb the electromagnetic wave with the corresponding wavelength. The energy carried by the electromagnetic wave in the UV-Visible spectrum is high enough so that the absorbance in this spectrum can be related to orbital electronic transitions from ground state to excited state (Schmid, 2001). In the UV-Visible spectrum range, the absorbance of organic matter is dominated by electronic transitions of energy levels of $\pi$ (bonding) to the level above $\pi^{*}$ (nonbonding) (Antosiewicz \& Shugar, 2016; Clark, 2016; Shah et al., 2015). The higher the absorbance is, the greater the chance of excitation of $\pi \rightarrow \pi^{*}$ is. This electronic excitation plays a big role in the process of molecular radicalization as a consequence of the bond weakening between $\mathrm{C}$ atoms. Thus, the $\mathrm{HC}$ molecules react more easily with $\mathrm{O}_{2}$. In other words, absorbance intensity level of UV-Vis light is related to molecular binding power. (Faris et al., 2012)

Figure 3 (a) shows the intensity of magnetized fuel absorbance scanned using a UVVis spectrophotometer. Within the given spectrum range, there are four absorbance peaks. It is observed that in the wavelength range of 290 - $390 \mathrm{~nm}$ (UV), the absorbance level of magnetized fuel changes against the intensity of the inducing magnetic field. This indicates an impact of the intensity of magnetic field exposure on the characteristics of fuel absorption in UV. The absorption level of UV from magnetized fuel increases along with the strengthening of the magnetic field intensity. This result is in line with previous studies (Faris et al., 2012). It is also shown in Figure 3 (b) that the absorbance intensity of each peak also increases along with the strengthening of the magnetic field. This pattern of increase is confirmed by the absorbance spectrum examination previously performed by Nufus with FTIR spectrophotom- 
eter in the magnetic field exposure range of 0 - 1500 Gauss (Nufus et al., 2017a).
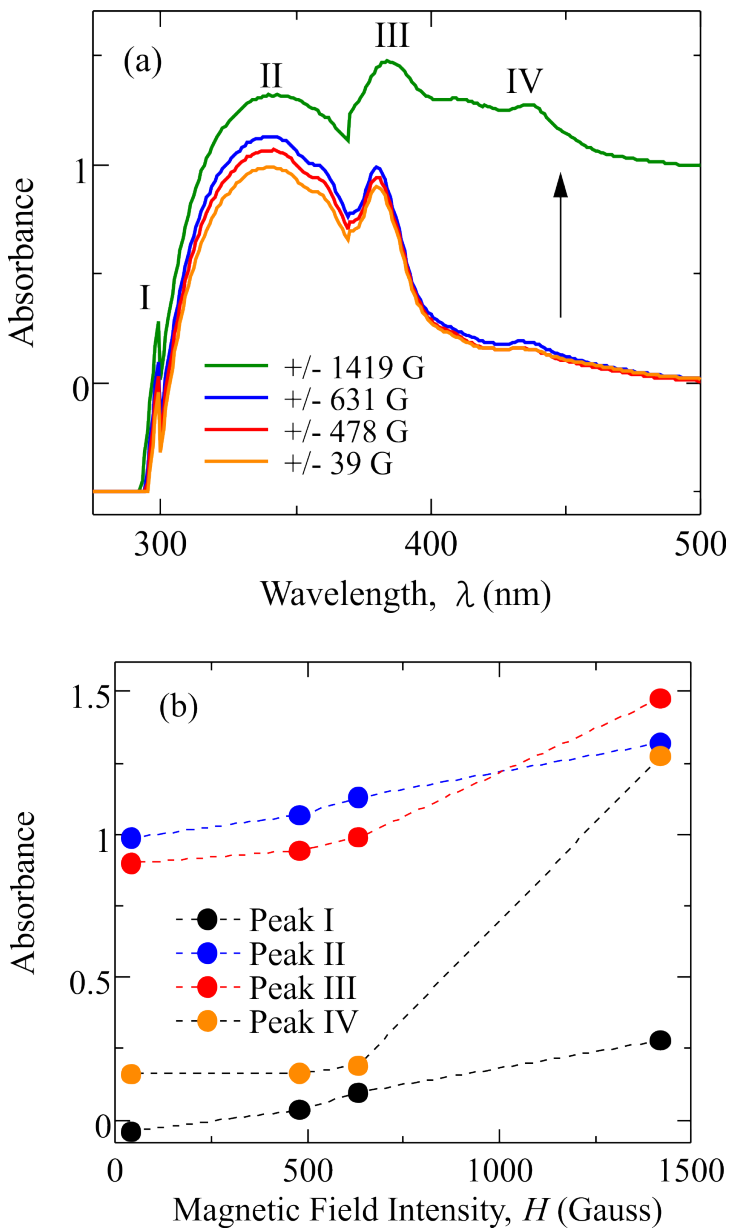

Figure 3. (a) Absorbance spectrum of UV-Vis from magnetized fuel, (b). Absorbance intensity of the peaks

\section{Combustion Efficiency Test}

In general, combustion process is an interaction between $\mathrm{HC}$ molecules of fuel and $\mathrm{O}_{2}$ with the following chemical equation: (Schell et al., 1988)

$$
\mathrm{CH}_{4}+2 \mathrm{O}_{2} \rightarrow \mathrm{CO}_{2}+2 \mathrm{H}_{2} \mathrm{O}
$$

The heat generated by the reaction is used to drive the motor. Naturally, the interaction between $\mathrm{O}_{2}$ and $\mathrm{C}$ atom in $\mathrm{HC}$ molecules faces problems due to the inter-molecular $\mathrm{HC}$ bonds (molecular clustering). Theoretically, if the inter-molecular $\mathrm{HC}$ bond is weakened, the distance between molecules will extend and $\mathrm{O}_{2}$ will reach the $\mathrm{C}$ atom more easily and react, so that the combustion process will be more optimal. The optimum combustion process will improve engine performance, thus making the fuel consumption more efficient.
The impact of strengthening of magnetic field exposure on fuel consumption is presented in Figure 4. Fuel consumption decreases along with the magnetic field strengthening. This result is in line with the research conducted by Guo (n.d), where at field exposure of $<2 \mathrm{kG}$, the decline rate of viscosity increases dramatically. As discussed earlier, fuel viscosity is related to molecular bonds and affects combustion performance. The decrease of fuel consumption occurs because the energy of the $\mathrm{HC}$ molecules in the fuel experiences an increase in the form of magnetic energy. This increase of energy narrows the energy gap, making it easier to excite molecules at higher energy level and cause the weakening of molecular bonds. This increase of molecular energy occurs because of changes in the magnetic moment orientation.

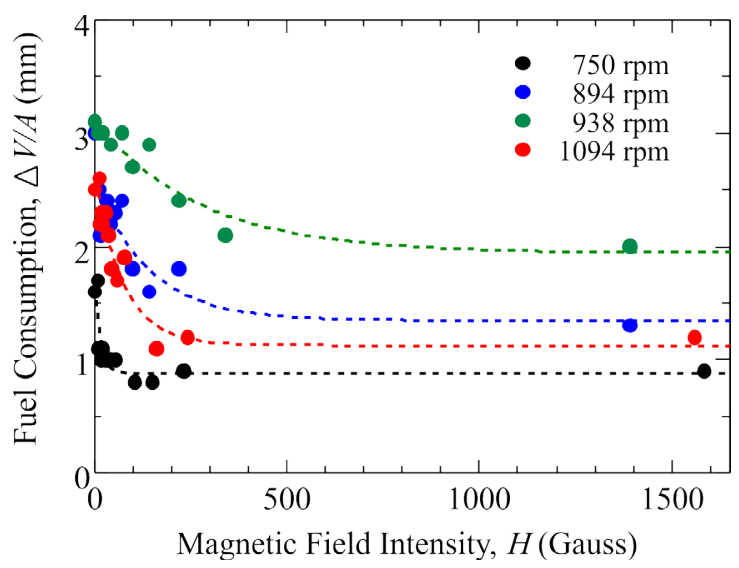

Figure 4. Impact of strengthening of magnetic field exposure on fuel consumption

Molecular magnetic energy exposed to external magnetic field is expressed by Equation 3:

$$
E=-\mu \cdot H
$$

with $\mu$ and $\mathbf{H}$ respectively are vectors of magnetic moments and external magnetic field. When the direction of the magnetic moments changes due to external magnetic field exposure, the energy difference can be calculated using the following equation:

$\Delta E=-\Delta \boldsymbol{\mu} \cdot \mathbf{H}=\left(\boldsymbol{\mu}_{1}-\boldsymbol{\mu}_{2}\right) \cdot \mathbf{H}$

This energy difference will reach its maximum value if the directions of $\mu_{1}$ and $\mu_{2}$ are opposite to each other. The increase of energy, followed by the weakening of molecular bonds, will extend the distance between molecules, thus increasing the probability of $\mathrm{HC}$ molecules 
to react with $\mathrm{O}_{2}$. In sum, exposure to magnetic field causes de-clustering of $\mathrm{HC}$ molecules. The physical behavior of magnetized HC molecules is illustrated in Figure 5.

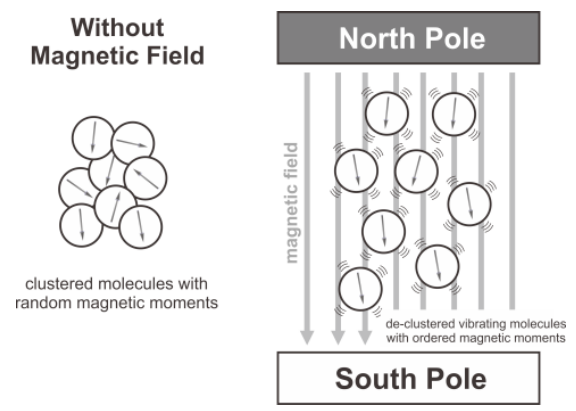

Figure 5. Physical behavior of magnetized HC molecules

It is also observed from Figure 4 that magnetized fuel consumption decreases exponentially against the increase of magnetic field intensity. This exponential decrease of consumption can be explained using the following Arrhenius principle:

$N \sim \exp \left(\frac{-E}{k_{\mathrm{B}} T}\right)$

with $N, E, k_{\mathrm{B}}$, and $T$ respectively are the number of molecules, energy gap, Boltzman constant, and absolute temperature (Nufus et al., 2017a). At fixed temperature and increasing magnetic energy, the energy gap will decrease so that the number of reacting molecules increases. Drastic decrease of fuel consumption occurs at low magnetic field exposure and starts to slope slightly on larger magnetic field. This shows that at larger magnetic field exposure, the magnetic moment is almost saturated so that the molecular magnetic energy approaches its maximum value.

Figure 6 shows the amount of $\mathrm{O}_{2}$ in the exhaust gas at various magnetic field intensities with four different engine loads. The amount of $\mathrm{O}_{2}$ in the exhaust gas decreases along with the strengthening of the magnetic field. According to the basic reaction of combustion (Equation 2), this decrease indicates the increased amount of $\mathrm{O}_{2}$ that reacts with the $\mathrm{HC}$ molecules. This result also confirms other results previously described in this paper (Figures 2, 3, and 4) that strengthening of the magnetic field exposure increases the completion level of combustion.

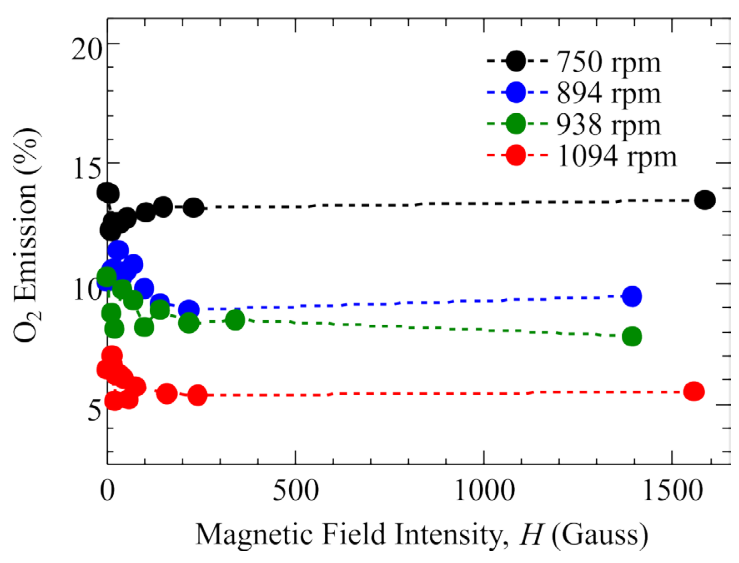

Figure 6. Impact of strengthening of magnetic field exposure on $\mathrm{O}_{2}$ content in exhaust gas emission

From Figure 6, it is also observed that the $\mathrm{O}_{2}$ emission will decrease when the engine load increases. This result is supported by Tao (2006) who, in his research, found that oil viscosity will decrease as the engine rotates faster. This decrease in viscosity indicates a bond weakening between molecules, which results in an increase of reaction between the $\mathrm{HC}$ molecules and $\mathrm{O}_{2}$.

\section{CONCLUSION}

The impacts of strengthening of magnetic field exposure on low-octane fuel on the completion level of combustion engine of a 2-stroke engine with cylinder of 49 cc have been studied. The result of this study indicates that strengthening of the magnetic field exposure can improve the completion level of combustion process by increasing the chance of reaction between hydrocarbon molecules and oxygen. The increase of reaction between hydrocarbon molecules and oxygen arises because of the bond weakening, accompanied by the increase of molecular vibrational energy.

Based on the investigation resuts and characterization carried out, it is necessary to optimize the design of magnetic field sources, both in terms of geometry and source type (using permanent magnets or coils). Optimizing the placement of magnetic resources in the system also needs to be done for it to be technically applied. In addition, further studies are needed regarding the long-term impacts of magnetic field exposure on combustion performance. 


\section{REFERENCES}

Abdel-Rehim, A. A., \& Attia, A. A. A. (2014). Does Magnetic Fuel Treatment Affect Engine's Performance? (SAE Technical Paper). Warrendale, PA: SAE International. doi:/10.4271/2014-01-1398

Antosiewicz, J. M., \& Shugar, D. (2016). UV-Vis Spectroscopy of Tyrosine Side-Groups in Studies of Protein Structure. Part 1: Basic Principles and Properties of Tyrosine Chromophore. Biophysical Reviews, 8(2), 151161. doi:10.1007/s12551-016-0198-6

Chalid, M., Saksono, N., Adiwar, \& Darsono, N. (2005). Studi Pengaruh Magnetisasi Sistem Dipol Terhadap Karakteristik Kerosin. Makara Journal of Technology, 8(8), 36-42.

Clark, J. (2016, May). UV-Visible Absorption Spectra. Retrieved December 14, 2018, from https://www.chemguide.co.uk/ analysis/ uvvisible/theory.html

Faris, US, Al-Naseri, SK, Jamal, N., I sse, R., Abed, M. Fouad, Z., Abas, A. (2012). Effects of Magnetic Field on Fuel Consumption and Exhaust Emissions in Two-Stroke Engines. Energy Procedia, 18, 327-338. http://doi. org/10.1016/j.egypro. 2012.05.044

Guo, H., Liu, Z., Chen, Y., \& Yao, R. (2011). A study of magnetic effects on the physicochemical properties of individual hydrocarbons. Logistical Engineering College, Chongqing, 400042, 216-220.

Hamdhani, M., \& Sudarmanta, B. (2016). Studi Eksperimental Variasi Kuat Medan Magnet Induksi Pada Aliran Bahan Bakar Terhadap Unjuk Kerja Mesin SINJAI 650 CC (Studi Kasus: Mapping Sumber Tegangan Induksi Magnet). Jurnal Teknik ITS, 5(2), 1-7.

Jain, S., \& Deshmukh, S. (2012). Experimental Investigation of Magnetic Fuel Conditioner (M.F.C) in I.C. engine. IOSR Journal of Engineering, 2(7), 27-31. doi:10.9790/302102712731

Lachenal, G., \& Ozaki, Y. (1999). Advantages of Near Infrared Spectroscopy for the Analysis of Polymers and Composites. Macromolecular Symposia, 141(1), 283-292. doi:10.1002/ masy. 19991410123

Mane, D. R., \& Sawant, V. S. (2015). A Comparative Study of Effect of Magnetic Field on Exhaust Emission in Internal Combustion Engine. IOSR Journal of Applied Physics, 7(6), 38-40.

Nufus, T. H., Setiawan, R. P. A., Hermawan, W., \& Tambunan, A. H. (2017a). The Effect of Electro Magnetic Field Intensity to Biodiesel Characteristics. Jurnal Pendidikan Fisika In- donesia, 13(2), 119-126. doi:10.15294/jpfi. v13i2.9477

Nufus, T. H., Setiawan, R. P. A., Hermawan, W., \& Tambunan, A. H. (2017b). Characterization of Biodiesel Fuel and its Blend after Electromagnetic Exposure. Cogent Engineering, 4(1), 1362839. doi:10.1080/23311916.2017. 1362839

Okoronkwo C. A., Nwachukwu, C.C., Ngozi -Olehi L.C., \& Igbokwe, J.O. (2010). The Effect of Electromagnetic Flux Density on the Ionization and the Combustion of Fuel (An Economy Design Project), American Journal of Scientific and Industrial Research, 1(3), 527531. doi:10.5251/ ajsir.2010.1.3.527.531

Pasquini, C. (2003). Near Infrared Spectroscopy: Fundamentals, Practical Aspects and AnaIytical Applications. Journal of the Brazilian Chemical Society, 14(2), 198-219. doi:10.1590/S0103-5053200300020 0006

Schell, M., Schram, H. M., \& Ross, J. (1988). Efficiency of a Combustion Reaction in Power Production. The Journal of Chemical Physics, 88(4), 2730-2734. doi:10.1063/1.454003

Schmid, F. (2001). Biological Macromolecules: UVvisible Spectrophotometry. John Wiley \& Sons Ltd. doi:10.1038/npg.els.0003142

Shah, R. S., Pawar, R. B., \& Gayakar, P. P. (2015). UV - Visible Spectroscopy - A Review. International Journal of Institutional Pharmacy and Life Sciences, 5(5). Retrieved from http:// www.ijipls.com/ uploaded/journal_files/15102 4111056.pdf

Silva, M. A. A., Correa, R. A., Tavares, M. G. de O., \& Filho, N. R. A. (2015). A New Spectrophotometric Method for Determination of Biodiesel Content in Biodiesel/Diesel Blends. Fuel, 143, 16-20. doi:10.1016/j.fuel.2014.10.048

Tao, R., \& Xu, X. (2006). Reducing the Viscosity of Crude Oil by Pulsed Electric or Magnetic Field. Energy \& Fuels, 20(5), 2046-2051. doi:10.1021/ef060072x

Vallance, C. (2017). An Introduction to Chemical Kinetics. Morgan \& Claypool Publishers. doi:10.1088/978-1-6817-4664-7

Vivek, U., Nikhil, B., \& Lutade, S. (2013). Performance of Spark Ignition Engine Under The Influence of Magnetic Field. International Journal of Research in Aeronautical and Mechanical Engineering, 1(3), 36-43.

Yu, J., Wang, H., Zhan, J., \& Huang, W. (2018). Review of recent UV-Vis and Infrared Spectroscopy Researches on Wine Detection and Discrimination. Applied Spectroscopy Reviews, 53(1), 65-86. doi:10.1080/05704928. 2017.1352511 